\title{
INFECCIÓN URINARIA EN PEDIATRÍA
}

M argarita A rdila M D*, M arcela R ojas M D**, Gina Santisteban M D**, A ndrea Gamero M D** A ngélica Torres M D**

\section{Resumen}

La infección de las vías urinarias es una patología frecuente en la edad infantil, por lo que el médico general, el pediatra y los involucrados en el diagnóstico y manejo del niño afectado están en la obligación de conocer las actualizaciones sobre el mecanismo fisiopatológico, métodos diagnósticos y tratamientos actuales. Se hace énfasis en la prevención, el uso racional de antibioticoterapia y los nuevos enfoques terapéuticos que se pueden ofrecer.

Palabras clave: infección del tracto urinario, pielonefritis, sepsis, diagnóstico, tratamiento.

Abreviaturas: ITU, infección del tracto urinario; RVU, reflujo vesicoureteral.

\section{URINARY TRACT INFECTION IN CHILDREN}

\section{Abstract}

Urinary tract infection (UTI) is a common illness in children, thus the general practitioner, the pediatrician and those involved in the diagnosis and management of the affected child must keep updated on UTI physiopathology, diagnostic methods and current treatments. We emphasize on prevention, rational use of antibiotic therapy and new therapeutic approaches available.

Key words: urinary tract infection, pyelonephritis, sepsis, diagnosis, treatment.

Fecha recibido: septiembre 18 de 2014 - Fecha aceptado: octubre 29 de 2014

* Pediatra Hospital de San José. Profesor Titular, Fundación Universitaria de Ciencias de la Salud. Bogotá DC, Colombia.
** Residente III de Pediatría, Fundación Universitaria de Ciencias de la Salud. Bogotá DC, Colombia. 


\section{Introducción}

La infección del tracto urinario (ITU) es una patología frecuente en la infancia y corresponde a un buen porcentaje de las visitas al servicio de urgencias pediátricas. ${ }^{1-4}$ Es reconocida como causa de enfermedades agudas y crónicas con una gran morbilidad. ${ }^{2}$ Por tanto es crucial conocer la patogénesis de la infección urinaria, los factores de riesgo, diagnóstico y el uso apropiado de antibióticos en nuestro medio..$^{2,5-8} \mathrm{La}$ ITU tiene una al ta incidencia durante la infancia apareciendo en cerca de $7 \%$ de los niños febriles menores de un año y es un indicador de anomalías anatómicas, como el reflujo vesicoureteral (RVU), y funcionales. EI RVU aparece en $25 \%$ de las primeras infecciones urinarias, siendo el $85 \%$ de estos casos de bajo grado ${ }^{9}$ y se relaciona con recurrencia de ITU y cicatrices, siendo estas últimas las determinantes del riesgo de daño renal ${ }^{2}$ EI diagnóstico a tiempo de una ITU y su tratamiento adecuado pueden prevenir complicaciones a corto plazo como una pielonefritis severa o sepsis de origen urinario que aparece hasta en $30 \%$ de recién nacidos y $20 \%$ en lactantes menores de tres meses ${ }^{3}$, así como secuelas a largo plazo que incluyen cicatrices renales las cuales tendrán una mayor incidencia en los menores de un año (5-10\%), hipertensión arterial y por último insuficiencia renal crónica y necesidad de trasplante. ${ }^{10}$ Por todo lo anterior es de gran importancia tener conceptos claros y actualizados. Para lograrlo se hace una revisión de la literatura acerca de la definición y demás ítems mediante búsqueda basada en términos definidos por descriptores en ciencias de la salud (DECS), utilizando las bases de datos en inglés de PUBMED, HINARI, OVID y datos en español de LILACS y SCIELO. Se revisaron 60 artículos, 50 en texto completo, los cual es se incluyen por pertinencia y novedad.

\section{Definición}

Infección urinaria: es la invasión, multiplicación e inflamación por un uropatógeno reconocido en cualquier localización del tracto urinario. 2,3,11

Bacteriuria: presencia de bacterias en la orina con 0 sin infección de vías urinarias. ${ }^{3,12}$
Bacteriuria significativa: aislamiento de un uropatógeno en un cultivo de orina, más de 100.000 unidades formadoras de colonias (UFC/ml) por micción espontanea, de cualquier crecimiento bacteriano por punción suprapúbica, o de 10.000 a 50.000 UFC por sonda vesical. ${ }^{3} \mathrm{~L}$ a bacteriuria se puede clasificar a su vez en sintomática que corresponde a la verdadera infección de vías urinarias, asintomática y complicada.

La primera se clasifica por su localización 2,3: pielonefritis conocida también como ITU alto. Se localiza a nivel del sistema pielocalicial y parénquima renal. ${ }^{2-10}$ Se caracteriza por fiebre alta (mayor o igual a $38.0^{\circ} \mathrm{C}$ ) ${ }^{13}$, lo que hace que en la actualidad se conozca como ITU febril, asociada con síntomas sistémicos, dolor abdominal, malestar general, náuseas, emesis y diarrea ocasional. Es más frecuente en menores de dos años y puede ser complicada. Cistitis, Ilamada ITU bajo. Se debe a la inflamación de la mucosa vesical con urgencia, disuria, frecuencia y hematuria. No se asocia con fiebre o compromiso sistémico. ${ }^{10}$ Se presenta en niñas mayores de dos años y por lo regular no hay malformación anatómica de base.,3 U retritis, inflamación de la mucosa uretral con síntomas como disuria, frecuencia, enuresis secundaria, piuria y bajo recuento de colonias en la orina $\left(<10^{3}\right) \cdot{ }^{13} \mathrm{~L}$ a bacteriuria asintomática es un hallazgo incidental en un niño por lo demás sano y asintomático con un recuento significativo de colonias bacterianas en el urocultivo. ${ }^{13}$ L a bacteriuria complicada cursa con un recuento significativo de colonias bacterianas en el urocultivo en un paciente con alteración anatómica o funcional de base (hidronefrosis, hidrouréter y RV U entre otros). 2,3,13

A su vez la infección urinaria puede clasificarse en ${ }^{2}$ : recurrente con aislamiento del germen después de haber tenido un cultivo estéril; recaída, aislamiento del mismo patógeno a pesar del manejo antibiótico adecuado; y reinfección, aislamiento de un germen diferente después de dos semanas del tratamiento inicial.

\section{Epidemiología}

L a ITU constituye uno de los principales motivos de consulta en el servicio de urgencias de pediatría en nuestro medio y a nivel mundial, correspondiendo al 
$14 \%$ de las visitas al año. ${ }^{13}$ Se considera una prevalencia de 4 a $7 \%$ en menores de dos años con fiebre de origen desconocido, siendo este el grupo etáreo de más al to riesgo. 3,4,8,14 L a prevalencia de ITU está entre 2.1 y $5.2 \%$ con una distribución por sexo de $0.7 \%$ en niñas y $2.7 \%$ en niños en el primer año de vida, entre el año y los cinco se observa una distribución de 0,9 a $1,4 \%$ en las niñas y de 0,1 a $0,2 \%$ en los varones por año. 2,3,11,12 Los menores de seis meses no circuncidados tienen 10 a 12 veces mayor riesgo $0^{1-3,12}$, aunque este procedimiento se considera benéfico solo en aquellos con alto riesgo de recurrencia (RVU 0 ITU recurrente) donde la circuncisión reduce la posibilidad de una nueva ITU en 10 a $30 \%$. No se ven iguales beneficios en los de bajo riesgo (N NT 4-11:1 Vs NNT 111:1). ${ }^{15}$ En adolescentes la incidencia de ITU es de $2 \%$ siendo prevalente en el sexo femenino. ${ }^{13}$ Se considera que de 50 a $80 \%$ de las ITU con compromiso clínico pueden cursar con pielonefritis. Los menores de dos años son los que presentan mayor posibilidad de desarrollarla, siendo un riesgo para cicatriz e insuficiencia renal crónica, por lo que se hace importante la identificación de estos niños para estudiarlos, instaurar tratamiento temprano y realizar seguimiento. ${ }^{3,5,6,8} \mathrm{~L}$ a recurrencia de ITU antes del año de vida es cerca de $75 \%$ en los niños y después del primer año de vida las niñas presentan recurrencias en $40 \%$ y los varones en $30 \%{ }^{6}$

\section{Factores predisponentes}

Se ha demostrado que pueden ser por una interacción entre factores del huésped, que depende de la función e integridad del tracto urinario, competencia del sistema inmune innato y de la virulencia bacteriana. ${ }^{16-18}$ L oS más importantes son:

- Las mujeres tienen mayor riesgo por ser la uretra más corta.

- No circuncisión.

- Hipercalciuria: se recomienda su determinación en infecciones urinarias recurrentes.

- Presencia de alteraciones anatómicas o funcionales del tracto urinario.
- Fenotipo sanguíneo p1: mayor tendencia a ser portador de E. coli P fimbrias (+), favorecen su adhesión al endotelio urinario.

- Estreñimiento y síndrome de eliminación disfuncional: se considera anormal menos de 4 micciones por día y de 3 deposiciones a la semana. Los hábitos miccionales o de higiene poco adecuados (retención urinaria, mala técnica de limpieza perineal).

- Diagnóstico previo de pielonefritis aguda e infecciones urinarias previas recurrentes.

- Menores de dos años.

- Retardo en iniciar el tratamiento antibiótico (no baja el riesgo de cicatrices renales).

- U ropatía obstructiva y vejiga neurogénica.

- Colonización fecal y perineal.

- Estados de inmunodepresión.

- A ctividad sexual o abuso sexual.

- Embarazo.

- Polimorfismos en el factor de crecimiento endotelial vascular y factor de crecimiento B 1.16,19

- Presencia de sondas o catéteres.

\section{Etiología}

L a mayor parte de los agentes causantes son bacterias de origen entérico $2,3,93 \%$ gram negativos, $6 \%$ cocos gram positivos y $1 \%$ levaduras, virus, protozoarios 0 parásitos. Dentro de los patógenos más comunes en la ITU están ${ }^{3,8,11}$ E scherichia coli 76-90\% ${ }^{3}$, K lebsiella $0.5-8 \%$, Proteus sp. $0.5-6 \%$, Stafilococcus sp. $1-5 \%$, Enterococcus 8\%, Pseudomonas 2-6\% y Serratia $0.8 \%$. La Pseudomona aeruginosa es el patógeno más frecuente en adultos. Se puede encontrar en niños que han recibido largas profilaxis o antibioticoterapia reciente durante el curso de una hospitalización. ${ }^{20}$ También se puede producir ITU de tipo vírico (adenovirus y $B K$ virus) como causa de cistitis. Las infecciones por hongos como cándida se pueden encontrar en niños inmunocomprometidos, diabéticos o con cateterismo 
vesical permanente, en especial si han recibido manejo antibiótico por largo tiempo. ${ }^{10}$ Por lo general, las infecciones nosocomiales son más difíciles de tratar y están causadas por distintos organismos, como E . coli, Candida, Enterococcus, Enterobacter y Pseudomona. ${ }^{2,8}$

\section{Patogenia}

Una vez la bacteria alcanza el tracto urinario puede ser expulsada por el vaciado de la orina 0 adherirse al uroepitelio. En este momento factores de virulencia como las diferentes clases de fimbrias pueden ayudar a favorecer que se presente la infección. ${ }^{21} \mathrm{EI}$ microambiente del tracto urinario, como las anormalidades anatómicas del mismo, el estado del uroepitelio y el flujo urinario adecuado, son la clave para el desarrollo o no de una infección urinaria, por tanto la severidad se relaciona con la virulencia de la bacteria, la capacidad de adherencia al epitelio de la vía urinaria, la presencia de fimbrias en la superficie de la bacteria y la susceptibilidad del huésped. ${ }^{2,19}$ El proceso comienza con la fijación bacteriana y la invasión de las células epiteliales de la vejiga; los polisacáridos bacterianos activan los receptores del uroepitelio (Toll like receptors) que reconocen estos antígenos bacterianos, activan el sistema inmune local e inician una respuesta que involucra el factor nuclear kB y la producción de citoquinas y quemoquinas. En particular los niveles de interleuquina-6 (IL-6) y el factor de necrosis tumoral alfa se correlacionan con el grado de inflamación. A sí, al tos niveles de citoquinas cursan con mayor respuesta inflamatoria. Estas son producidas por células epiteliales de la vejiga, uréter, uretra y riñón, así como por los neutrófilos polimorfonucleares (PM Ns) y macrófagos. ${ }^{16,19,22}$

Dentro de los mecanismos de defensa del tracto urinario están el pH ácido de la orina; el flujo descendente de orina del riñón a la vejiga y su vaciamiento por la uretra; la proteína de Tamm-H orsfall que se adhiere a las fimbrias tipo I de la E. coli participa en la defensa del huésped, evita su fijación, disminuye la lesión e inflamación y posterior desarrollo de infección; la inmunoglobulina A secretora ${ }^{2,16,19,23 ;}$ y la diseminación hematógena que es más frecuente en los neonatos y lactantes pequeños, en quienes a partir de un cuadro de bacteriemia se produce la infección del parénquima renal. ${ }^{24}$ Después de esta edad la vía ascendente es la principal ruta. ${ }^{23}$

\section{Manifestaciones clínicas}

En los neonatos es rara la fiebre y suel en presentar irritabilidad, decaimiento, rechazo del alimento y vómito. Los lactantes a menudo presentan fiebre mayor de $39^{\circ} \mathrm{C}$ y cuando dura más de dos días se correlaciona con ITU. Este es el signo más común. De hecho, en todos los lactantes con fiebre sin ningún otro foco que la explique, el primer diagnóstico que hay que tener en cuenta es ITU. O tros signos son vómito, pobre succión, deshidratación, letargia o irritabilidad, retardo pondoestatural, sensibilidad suprapúbica, Ilanto y pujo con la micción, hematuria, orina fétida, oliguria o poliuria. ${ }^{8,24}$ L os niños mayores pueden referir manifestaciones más específicas como dolor en el costado y malestar general cuando se trata de una pielonefritis aguda y síntomas miccionales (disuria, tenesmo urinario e incontinencia) en el caso de infección de las vías urinarias bajas. Se han realizado estudios con el fin de que los síntomas y signos tengan un valor predictivo positivo para el diagnóstico de ITU. En una revisión realizada por Sahsi y Carpenter encontraron que los más útiles para predecir la ITU fueron: a) antecedentes de infección urinaria; b) temperatura superior a $39^{\circ} \mathrm{C}$; c) duración de la fiebre de más de 48 horas d) dolor suprapúbico y e) no estar circuncidado, en el caso de los varones. Cuanto más al to puntaje mayor era la probabilidad de tener ITU. Por otra parte, en dos estudios realizados por Gorelick y col. se concluye que si existen tres o más de los siguientes datos está indicado real izar pruebas para diagnosticar una posible ITU : a) raza blanca; b) edad $<12$ meses; c) temperatura $>39^{\circ} \mathrm{C}$; d) ausencia de otro foco que justifique la fiebre y e) fiebre de dos 0 más días de evolución. ${ }^{25,26}$ Siempre se debe realizar un examen físico completo, tomar signos vitales, tensión arterial, temperatura, frecuencia cardíaca y medidas antropométricas, descartar masas abdominales, practicar examen genitourinario con exploración escrotal en todos los niños para evaluar epididimitis y fimosis. Se debe examinar la región sacra en busca de hoyuelos, fositas o una almohadilla grasa, ya que la presencia de estos signos se puede 
asociar con malformaciones anatómicas y/o funcionales. Los niños con ITU suelen presentar signos y síntomas sugestivos de infecciones gastrointestinales y respiratorias. En consecuencia se debe considerar esta patología en todos los niños con enfermedad grave, aunque muestren evidencia de infección ajena al tracto urinario. ${ }^{2}$

\section{Diagnóstic o: uroanálisis}

El diagnóstico presuntivo es el uroanálisis pero la confirmación diagnóstica requiere el aislamiento de un uropatógeno en el cultivo. L a A cademia A mericana de Pediatría (AAP) recomienda en el lactante menor de dos años que no controla esfínteres la recolección de la muestra de orina para el uroanálisis y el urocultivo mediante dos métodos: punción suprapúbica y cateterismo vesical transuretral. ${ }^{10,25}$

Punción suprapúbica: se considera el método estándar libre de contaminación por la flora perineal si el paciente no controla esfínteres. Es la única al ternativa aceptable en niños con fimosis moderada a severa y niñas con alteraciones en labios mayores y menores. Puede ser fallida en 23 a 99\%, 2, 3, 8, 10, 25, 27

Cateterismo vesical transuretral: es confiable, siendo considerado positivo cuando el crecimiento del patógeno urinario es mayor de $50.000 \mathrm{UFC} / \mathrm{ml}$ (probabilidad $>95 \%$ ), entre $10.000 \mathrm{a}<50.000 \mathrm{UFC} / \mathrm{ml}$ puede ser una infección probable y con recuentos menores de 10.000 UFL/ml la infección es poco probable. Es un procedimiento invasivo y doloroso para el paciente. ${ }^{2-4,8,27}$

Micción espontánea: cuando hay control de esfínteres se puede tomar la muestra en la mitad de la micción espontánea, previo aseo adecuado de genitales. Es positivo si se obtienen más de $100.000 \mathrm{UFC} / \mathrm{ml}$ con una probabilidad de infección del $80 \%$ si es obtenido de una sola muestra y de $95 \%$ en tres muestras, idéntico germen y en la misma cantidad, situación que aumenta los costos. ${ }^{1,3}$ Entre 10.000 a $<100.000$ U FC/ $\mathrm{ml}$ se considera dudoso y < de10.000 UFC/ml es negativo. Es menos confiable por la mayor probabilidad de contaminación, pero es útil para el seguimiento de los pacientes, más que para el diagnóstico inicial. ${ }^{8}$
Bolsa recolectora: este método no es recomendable por la gran tasa de contaminación que termina en falsos positivos (50-57\%). 2,8 Es un poco más confiable con adecuado aseo y dejando la bolsa por períodos máximos de 30 minutos antes de recoger la muestra. En lactantes por la al ta probabilidad de contaminación la especificidad cae entre $63 \%$ y $88 \%$. Se utiliza para seguimiento, no como diagnóstico inicial. Si el urocultivo a partir de una bolsa perineal es negativo, se descarta ITU . 2,10,25 L a sensiblidad y especificidad del parcial de orina se observa en la (Tabla 1). ${ }^{28}$

\begin{tabular}{|l|l|l|}
\hline \multicolumn{3}{|c|}{ Tabla I. Sensibilidad y especificidad en el } \\
parcial de orina \\
\hline \multicolumn{1}{|c|}{ Prueba } & $\begin{array}{c}\text { Sensibilidad \% } \\
\text { rango }\end{array}$ & $\begin{array}{c}\text { Especificidad \% } \\
\text { rango }\end{array}$ \\
\hline Leucocitos estearasa & $67-94 \%$ & $64-92 \%$ \\
\hline Nitritos & $15-82 \%$ & $90-100 \%$ \\
\hline $\begin{array}{l}\text { Recuento } \\
\text { microscópico de } \\
\text { leucocitos }\end{array}$ & $32-100 \%$ & $45-98 \%$ \\
\hline Bacterias & $15-100 \%$ & $10-100 \%$ \\
\hline
\end{tabular}

Tomada de Subcommittee on Urinary Tract Infection SCoQ. Urinary Tract Infection: Clinical Practice Guideline for the Diagnosis and Management of the Initial UTI in Febrile Infants and Children 2 to 24 Months. Pediatrics [Internet]. 20I I; I 28:[595-610 pp. $^{25}$

\section{Uroc ultivo}

Es la prueba diagnóstica de oro y confirmatoria de infección urinaria. 2,8 tiene significación clínica cuando el crecimiento es más de 100.000 unidades formadoras de colonias Se debe sembrar en los primeros 60 minutos después de la toma porque puede existir sobrecrecimiento de gérmenes contaminantes y obtener falsos positivos. El cultivo identifica el microorganismo causante y ofrece una guía acerca del manejo antibiótico adecuado. ${ }^{1}$

\section{Otras pruebas diagnósticas}

Si se sospecha sepsis deben realizarse hemocultivos y otras pruebas según el cuadro clínico. Los reactantes de fase aguda (VSG, PCR) tienen un V PP bajo para 
identificar pielonefritis aguda. ${ }^{1}$ LA PCR elevada tiene un $100 \%$ de sensibilidad pero una especificidad muy baja de $26 \%$. En cuanto a la procal citonina, los estudios muestran especificidad de $82 \%$ y sensibilidad de $70 \%$. Como marcador de infección se incrementa en caso de lesión del parénquima renal, pero aún faltan más estudios. ${ }^{29,} 30$

\section{Imágenes}

EI RVU se diagnostica en cerca de $50 \%$ de los niños que presentan ITU antes de un año de vida. ${ }^{2} \mathrm{EI}$ porcentaje de desarrollar cicatrices renales luego de una pielonefritis varía entre 10 y $30 \%$, lo cual es un factor de riesgo para hipertensión arterial y falla renal a largo plazo. ${ }^{31}$ Según las últimas guías de 2011 de la A A P las indicaciones para realizar imágenes diagnósticas en infección de vías urinarias han venido modificándose sobre todo si se trata del primer episodio. Para evitar la realización en forma indiscriminada se han establecido criterios para su uso. 1,14,32,33

\section{Ecografía renal}

L os criterios para realizar ecografía renal y de vías urinarias son los siguientes: 1) infección urinaria febril, 2) edad menor de un año, 3) todo lactante con primer episodio de ITU que no tenga una ecografía prenatal o posnatal normal, 4) masa abdominal o vesical, 5) pruebas de función renal al terada, 6) infección de vías urinarias por microorganismo diferente a $E$ coli, 7) infecciones urinarias recurrentes, 8) clínica sugestiva de al to riesgo de piel onefritis y 9) varones de cual quier edad con la primer ITU. 1, 25, 27

A unque tiene baja sensibilidad (50 a 60\%), permite valorar el parénquima, tamaño renal, espesor cortical, crecimiento del órgano y malformaciones anatómicas como ureterohidronefrosis, obstrucción ureteral, dilatación de uréter, características de la pared vesical y presencia de residuo., 1,7,31 Se recomienda su realización entre 48 y 72 horas de iniciado el tratamiento y estabilización clínica, permitiendo identificar complicaciones como abscesos renales, perirrenales 0 pionefrosis. El aumento en la ecogenicidad se puede relacionar con pielonefritis. ${ }^{1,3,11} \mathrm{~L}$ a sensibilidad y espe- cificidad del ultrasonido para pielonefritis aguda no es buena. ${ }^{1,3,11}$ En conclusión, en todos los niños con primer episodio de ITU se debe realizar ecografía renal y de vías urinarias, debido a que se pueden encontrar hasta $12 \%$ de anormalidades. ${ }^{2,7,25}$

\section{Gammagrafía con DMSA-TC 99 M}

Es el estándar de oro para diagnóstico y seguimiento de cicatrices renales. No se recomienda la realización rutinaria en la fase aguda de pacientes con primer episodio de ITU. Se considerara su uso según la disponibilidad y criterio. ${ }^{27}$ Las indicaciones son ${ }^{1,3}: 1$ ) en la fase aguda en caso de urocultivos positivos en pacientes con compromiso sistémico o infecciones urinarias recurrentes y 2 ) recién nacido con $\mathrm{RV} U$.

La realización de gammagrafía diferida a partir de los seis meses tras un primer episodio de ITU febril está indicada si la evolución es atípica (persistencia de fiebre más de 48 horas), ante la sospecha de masa abdominal o vesical, por creatinina elevada, infección de vías urinarias con germen diferente a $\mathrm{E}$. coli, ITU recurrente febril y cuando hay alteraciones en estudios imagenológicos realizados antes (ecografía o gammagrafía previa si se realizó).

La gammagrafía permite identificar tres tipos de alteraciones ${ }^{1}$ : defectos corticales renales, dilatación del sistema pielocalicial y aumento del tamaño del parénquima renal. Si la gammagrafía renal con DM SA es normal, la probabilidad de que desarrolle cicatrices renal es es muy baja. ${ }^{34}$

\section{Cistografía miccional conven- cional}

Es el método de elección para diagnosticar RVU y clasificarlo, así mismo detecta residuo postmiccional, valvas uretrales, ureteroceles y divertículos vesicales. ${ }^{1}$ No se debe realizar de rutina en el primer episodio de infección de vías urinarias. Se indica su utilización en pacientes que cumplan los siguientes criterios:1) niño o niña con ITU recurrente, recomendándose su realización después del segundo episodio de ITU ${ }^{35}$;2) antecedente de ecografía o gamagrafía previas altera- 
das; 3) antecedentes familiares de RV U; y 4) sospecha de anomalía del tracto urinario inferior. ${ }^{25,27}$

EI RVU se presenta hasta en $50 \%$ de los niños con pielonefritis. Con la cistografía miccional se diagnostica y clasifica el RVU y se valora la morfología de uretra, vejiga y uréteres. ${ }^{1,3}$ En las nuevas guías de 2011 ha sido reevaluada la importancia del RV U como predictor de daño renal, ya que se observó que la proporción de niños con RVU leve grado I y II (que son los más comunes asociados con infección urinaria) tienen bajo riesgo de daño renal, I c contrario ocurrirá si es severo (IV y V ) ${ }^{28}$, aunque el RVU de alto grado es de muy baja prevalencia. Por ser este procedimiento incomodo, invasivo y con exposición a radiación no se debe real izar de rutina. ${ }^{25} \mathrm{~N} 0$ es necesario esperar más de dos semanas después del tratamiento de la ITU para realizarlo en forma ambulatoria previo urocultivo negativo y paciente en manejo profiláctico con antibióticos. ${ }^{11} \mathrm{Es}$ un procedimiento invasivo, doloroso, requiere cateterización de la uretra y además conlleva un alto nivel de irradiación por lo cual solo se realiza una sola vez, los controles de seguimiento del RVU se hacen con cistografía isotópica. ${ }^{36}$ L as indicaciones de cistografía miccional convencional ${ }^{1}$ son: 1) niños menores de cinco años con pielonefritis, 2) varones con primera ITU independiente de la edad, 3) niñas menores de dos años con primera ITU con al teraciones en la ecografía o gammagrafía y 4) niños con ITU recurrente. Es el estudio de predilección en los varones con primer episodio de ITU. La cistografía isotópica a menudo se realiza en las niñas y para hacer seguimiento..$^{25,28}$

\section{Cistografía isotópica}

Es útil para seguimiento de RV U y para estudio de niñas con disfunción vesical. Tiene menor irradiación pero no permite clasificar el reflujo ni da información anatómica. No se recomienda para diagnóstico inicial. 1,3,7,12,27,33,37

\section{Urografía excretora}

No se debe realizar de rutina en la fase aguda. Solo en casos especiales de alteración anatómica antes de proceder con tratamientos quirúrgicos. ${ }^{12,37}$

\section{Tratamiento}

El objetivo es erradicar la infección, aliviar síntomas y minimizar el desarrollo de defectos del parénquima renal. ${ }^{38} \mathrm{~L}$ as indicaciones de hospitalización son: 1) tratamiento antibiótico parenteral, 2) lactantes menores de tres meses de edad, 3) compromiso sistémico, 4) inmunosuprimidos, 5) intolerancia a la vía oral, 6) deshidratación, 7) sospecha clínica y/o analítica de pielonefritis a cualquier edad y 8) en casos de no adherencia al manejo ambulatorio con dificultades en su seguimiento y control.

\section{Infec ción urinaria baja/c istitis}

Los pacientes sin compromiso sistémico que no lucen tóxicos, con adecuada tolerancia de la vía oral y familia confiable y comprometida con el cuidado y seguimiento, pueden manejarse en forma ambulatoria con antibióticos orales. ${ }^{2,3,14} \mathrm{En}$ niños mayores de dos años un tratamiento más corto ( 3 a 5 días) del usual (7 a 10 días) podría disminuir las recaídas y proveer los beneficios del curso corto de antibióticos. 2,3,14

L a revisión Cochrane de 2009 concluye que no hay diferencia entre un esquema antibiótico corto (2 a 4 días) y largo ( 7 a 14 días) en el tratamiento de infección urinaria baja, ambas opciones parecen iguales de efectivas. ${ }^{3,8,14,39} \mathrm{En}$ casos de respuesta clínica insatisfactoria o deterioro clínico con el manejo inicial, se debe hospitalizar el niño para ampliar la cobertura con una cefalosporina parenteral y un aminoglucósido. 2,3,40

\section{Pielonefritis}

En el lactante menor de tres meses febril, tóxico, con compromiso general y sospecha de pielonefritis aguda, se debe hospitalizar para el manejo con líquidos parenterales si lo requiere y la administración de antibiótico también parenteral. $2,3,8$

En recién nacidos y lactantes menores de tres meses febriles con riesgo de sepsis, además del urocultivo se les debe tomar hemocultivo y cultivo de líquido cefalorraquídeo antes del inicio del antibiótico pa- 
renteral. . 2,8 D eben recibir terapia biconjugada con un aminoglucósido más una penicilina; en los lactantes mayores de tres meses se sugiere monoterapia con una cefalosporina de primera generación. 2,3 Para el tratamiento de pielonefritis aguda en niños, la literatura mundial propone varios esquemas de manejo en cuanto a diferentes antibióticos, vías de administración y duración del tratamiento. Un metanálisis realizado por Cochrane en 2008 concluye en cuanto a la vía de administración la oral por 10 a 14 días, 0 antibiótico endovenoso por 2 a 4 días para continuar con antibiótico oral por diez días o solo endovenoso. A sí mismo recomienda el oral con cefixima, ceftibuten 0 amoxicilina y manejo endovenoso con cefalosporinas de tercera generación o aminoglucósidos. ${ }^{8}$ La A A P sugiere que los niños (dos meses a dos años) con sospecha clínica de pielonefritis deben recibir terapia endovenosa por tres a siete días; si hay respuesta clínica satisfactoria se continuará la vía oral y el antibiótico se elegirá según la sensibilidad del urocultivo inicial hasta completar 14 días. $^{2,3}$ En nuestro medio se recomienda el uso de cefalosporinas de primera generación debido a que aún no han ocurrido altas resistencias en pacientes no complicados. Se deben reservar las cefalosporinas de tercera generación (ceftriaxona) para casos muy puntuales de resistencia o riesgo de nefrotoxicidad. ${ }^{2}$ En el Hospital de San José de Bogotá DC, en las revisiones de 2006-2007 del comité de infecciones, se encontró que el germen más frecuente en infección urinaria es $\mathrm{E}$. coli con una resistencia a la cefalotina de $30 \%$, por lo que la recomendación es utilizar cefazolina que tiene una resistencia menor de $10 \%$ y continuar el manejo ambulatorio oral con cefal exina. El urocultivo de control está indicado si no hay adecuada respuesta clínica tras 48 horas de antibiótico (fiebre, compromiso sistémico) y en casos de resistencia en el antibiograma se procederá a un nuevo urocultivo previo al cambio antibiótico, se debe realizar ecografía renal para detectar obstrucciones agudas 0 abscesos. ${ }^{3}$ L a estancia hospitalaria dependerá de la respuesta clínica y el reporte del antibiograma. El egreso depende de si el paciente tolera vía oral, desaparecen los síntomas, y al menos 48 horas sin fiebre. Se recomienda un esquema antibiótico entre 10 y 14 días (Tabla 2).1,2,12,41
Tabla 2. Antibióticos más utilizados para el tratamiento de la infección urinaria en niños ${ }^{2}$

\begin{tabular}{l|l|l|l}
\hline Antibiótico & Dosis diaria & Fracciones & Vía admi-
\end{tabular}

Tratamiento parenteral

\begin{tabular}{|l|r|c|c|}
\hline Ceftriaxona & $75 \mathrm{mg} / \mathrm{Kg}$ & I-2 & IV \\
\hline $\begin{array}{c}\text { Cefazolina o } \\
\text { Cefalotina }\end{array}$ & $100 \mathrm{mg} / \mathrm{Kg}$ & 3 & IV \\
\hline Amikacina & $15 \mathrm{mg} / \mathrm{kg}$ & I & IV \\
\hline Ampicilina & $100 \mathrm{mg} / \mathrm{Kg}$ & 4 & IV \\
\hline
\end{tabular}

Tratamiento oral

\begin{tabular}{|c|r|c|c|}
\hline $\begin{array}{c}\text { Amoxicilina- } \\
\text { clavulánico }\end{array}$ & $40-80 \mathrm{mg} / \mathrm{kg}$ & 3 & VO \\
\hline Cefixima & $8 \mathrm{mg} / \mathrm{Kg}$ & $\mathrm{I}-2$ & VO \\
\hline Cefalexina & $50-75 \mathrm{mg} / \mathrm{Kg}$ & 4 & VO \\
\hline
\end{tabular}

Las fluoroquinolonas, como la ciprofloxacina, se pueden considerar en el tratamiento de ITU pediátrica. ${ }^{42}$ L as infecciones por hongos son raras en los niños sanos, los factores de riesgo para el desarrollo de funguria incluyen tratamiento prol ongado con antibióticos, uso de catéteres de drenaje urinario, nutrición parenteral y la inmunosupresión. La mayoría de los casos por hongos son causados por Cándida sp seguida por Aspergillus sp, Cryptococcus sp. y Coccidioides sp. La presentación clínica de la funguria va desde la ausencia de síntomas a la sepsis fulminante y el diagnóstico se logra por aspiración suprapúbica o sondaje vesical transuretral. L os cultivos de orina con más de 104 col/ $\mathrm{mL}$ se han utilizado como criterio para la terapia. Si es positivo se hará ecografía renal para buscar más focos de funguria. L os pacientes sintomáticos pueden tratarse mediante irrigación vesical diaria con anfotericina $50 \mathrm{mg} / \mathrm{L}$ durante siete días o en irrigación continua continua ( $42 \mathrm{~mL} / \mathrm{h}$ ) durante 72 horas.

\section{Profilaxis antibiótica}

La frecuencia de reinfección durante el primer año luego de una infección urinaria se estima en 20 a 30\%, siendo el objetivo de la profilaxis antimicrobiana mantener estéril la orina y así reducir el riesgo de estas recurrencias, a pesar de que las evidencias indican una 
eficacia leve. ${ }^{2,3,5-7,14,43} \mathrm{En}$ años recientes la resistencia bacteriana se ha ido incrementando en los pacientes con ITU. La resistencia de la E. Coli al TM P-SM X es de $25 \%$ y a la ampicilina de $40 \%$, a las cefalosporinas de primera generación de $25 \%$ y a las de tercera generación 3 a 4\%. ${ }^{44}$ Se debe volver a evaluar la necesidad y seguridad de un tratamiento profiláctico a largo plazo en niños con o sin RVU.1,3,5,6,45 En 2006 un estudio aleatorio controlado sobre antibióticos profilácticos en niños con RVU grado I-III o sin reflujo, no se evidenciaron efectos significativos en la prevención de infecciones urinarias recurrentes y cicatrices renales. ${ }^{1,7,45}$ Para niños con 0 sin reflujo primario leve la profilaxis no redujo la rata de recurrencia de ITU durante el primer año luego del primer episodio. Los pacientes con reflujo grado IV o V son de al to riesgo para infecciones urinarias recurrentes y daño renal, recomendándose la corrección quirúrgica. 1,5,46

Los arándanos han sido recomendados para la prevención y el tratamiento de la infección urinaria. L os agrios contienen ácido málico, ácido cítrico, ácido quínico, fructosa y glucosa. Se cree que la fructosa y la proancantocianidina inhiben la adhesión de galactosa específica a las fimbrias de E.Coli al revestimiento del epitelio urotelial de la vejiga. ${ }^{47}$ Varios estudios demuestran que aún falta evidencia para recomendar el uso del jugo de arándano y hay poca información en cuanto la dosificación y el tiempo que se debe administrar. ${ }^{48}$ En cuanto a probióticos, la evidencia prometedora del uso de al gunos en mujeres con infecciones urogenitales sugiere posibles beneficios, incluso en ITU infantil. Se deben estudiar estos probióticos como alternativa de antibióticos y profilaxis para prevenir la ITU. Es importante identificar la cepa de lactobacilos perjudiciales para uropatógenos mediante estudios clínicos. ${ }^{49}$

\section{Seguimiento}

Se controlará cada seis a doce meses la creatinina sérica, nitrógeno ureico y la relación proteinuria/creatinuria en muestra aislada de orina 0 de 24 horas, de acuerdo con la edad del niño. En los controles ambulatorios hay que monitorear la tensión arterial ya que la hipertensión es la complicación más frecuente (23\%) debida a cicatrices renales y en $10 \%$ puede cursar con insuficiencia renal crónica. La hi pertensión arterial, la proteinuria y el daño renal crónico son consecuencias de infecciones urinarias de diagnóstico tardío, malformaciones no diagnosticadas y manejos inadecuados. ${ }^{23}$

\section{Evolución y pronóstico}

En 1980 el Estudio Internacional de Reflujo en Niños (IRSC) inició un protocolo para comparar el resultado tanto de manejo médico o quirúrgico en niños con RV U grado III-IV no obstructivo. El estudio evidenció que el RV U de grado leve se resolvía en forma espontánea sin evidencia de nuevas cicatrices. En los 10 años de seguimiento no hubo diferencia significativa en los dos métodos de manejo en relación con la aparición de nuevas cicatrices, crecimiento renal o función renal. ${ }^{50} \mathrm{~L}$ a mayoría de las recurrencias ocurren dentro del primer año de vida. ${ }^{28} \mathrm{~L}$ as niñas luego de la primera infección urinaria, cerca de $50 \%$ estarían en riesgo de presentar una reinfección en el próximo año de vida y $75 \%$ en los dos años siguientes. ${ }^{12} \mathrm{C}$ ada vez que se presenta una nueva infección aumenta el riesgo de recurrencias hasta en $25 \% .{ }^{28}$ De 6 al $15 \%$ de las niñas con infección urinaria pueden desarrollar cicactrices secundarias, las cuales se evidenciarán dentro de los tres años posteriores a la infección urinaria. ${ }^{12} \mathrm{~A}$ mayor número de infecciones urinarias recurrentes aumenta la incidencia de nuevas cicatrices lo cual se traducirá en mayor riesgo de compromiso de la función renal y secuelas como hipertensión arterial e insuficiencia renal crónica. ${ }^{41} \mathrm{~L}$ a detección temprana de la pielonefritis es fundamental para preservar la función renal. Son muchos los estudios que han demostrado cómo un diagnóstico precoz de infección urinaria disminuye la aparición de cicatrices renales. ${ }^{28}$

\section{Referencias}

1. Bauer R, Kogan B. New developments in the diagnosis and management of pediatrics utis. U rol Clin N A m. 2008; 35(1):47-58.

2. Chang SL, Shortliffe LD. Pediatric urinary tract infections. Pediatr Clin North Am. 2006; 53(3):379-400

3. M alo G, Echeverry J, I ragorri S, Gastel bondo R. Infección U rinaria (IU ) en NiñoS M enores De 2 A ños. Guía de práctica clínica (GPC). [monografía en Internet]. Bogotá: Sociedad Colombiana de U rologìa; [citado 24 mar 2015]. Disponible en: http://scu.org.co/userfiles/file/guias/006.pdf.

4. L angley J M. D efining urinary tract infection in the critically ill child. Pediatr Crit Care M ed. 2005; 6(3 Suppl):S25-9. 
5. M ontini G, Rigon L, Zucchetta P, Fregonese F, Toffolo A, Gobber D, et al. Prophylaxis after first febrile urinary tract infection in children? A multicenter, randomized, controlled, noninferiority trial. Pediatrics. 2008; 122(5):1064-71.

6. M attoo TK. A re prophylactic antibiotics indicated after a urinary tract infection? Curr O pin Pediatr. 2009; 21(2):203-6.

7. Wald ER. Vesicoureteral reflux: the role of antibiotic prophylaxis. Pediatrics 2006; 117(3):919-22.

8. B ell LE, M attoo T. U pdate on childhood urinary tract infection and vesicouretera reflux. Semin N ephrol. 2009; 29(4):349-59.

9. Ismaili K, Wissing K M , L olin K, Le PQ, Christophe C, Lepage P, et al. Characteristics of first urinary tract infection with fever in children: a prospective clinical and imaging study. Pediatr Infect Dis J. 2011; 30(5):371-4.

10. Bhat RG, Katy TA, Place FC. Pediatric urinary tract infections. Emerg Med Clin North Am. 2011; 29(3):637-53.

11. M oreno Villamil M L, O sorio A rango L M, Gastelbondo A maya R, Gutierrez C. Correlación Diagnóstica entre criterios clínicos y paraclínicos con la gamagrafía DM SA en pielonefritis. [monografía en Internet]. B ogotá: Fundación Cardio Infantil. [citado 24 mar 2015]. Disponible en: http://encolombia.com/medicina/ revistas-medicas/pediatria/vp-393/pediatria39304-correlacion/.

12. U crós Rodriguez S. Guías de pediatría práctica basadas en la evidencia. 2a ed. Bogotá : Editorial M édica Panamericana, 2009.

13. Feld LG, M attoo TK. U rinary tract infections and vesicoureteral reflux in infants and children. Pediatr Rev. 2010; 31(11):451-63.

14. Williams G, Craig JC. Prevention of recurrent urinary tract infection in children Curr Opin Infect Dis. 2009; 22(1):72-6.

15. Singh-Grewal D, M acdessi J, Craig J. Circumcision for the prevention of urinary tract infection in boys: a systematic review of randomised trials and observational studies. A rch Dis Child. 2005; 90(8):853-8.

16. Storm DW, Patel AS, Koff SA, Justice SS. N ovel management of urinary tract infections. Curr Opin U rol. 2011; 21(4):328-33.

17. Tanaka ST, B rock JW. Pediatric urologic conditions, including urinary infections. M ed Clin N orth A m. 2011 J an;95(1):1-13.

18. Singh-Grewal D, M acdessi J, Craig J. Circumcision for the prevention of urinary tract infection in boys: a systematic review of randomised trials and observational studies. A rch Dis Child. 2005; 90(8):853-8.

19. M ontini $\mathrm{G}$, Tullus K, Hewitt I. Febrile urinary tract infections in children. N Engl J Med. 2011; 365(3):239-50.

20. Bitsori M, Maraki S, Koukouraki S, Galanakis E. Pseudomonas aeruginosa urinary tract infection in children: risk factors and outcomes. J U rol. 2012 Jan;187(1):260-4.

21. Clark CJ, Kennedy WA, Shortliffe LD. U rinary tract infection in children: when to worry. U rol Clin N orth A m. 2010; 37(2):229-41.

22. Dairiki Shortliffe $L M$. Infection and inflammation of the Pediatric genitourinary tract. En: Wein AJ, K avoussi LR,N ovick AC,Partin AW, Peters CA . CampbellWalsh U rology. Philadel phia: Saunders; 2010. p. 3085-121.

23. Restrepo de Rovetto C, de Castaño I, Restrepo Restrepo J M . Enfoques en nefrología pediátrica. Colombia: Camilo Torres Serna y Cia S.C.S; 2010.

24. M olina Cabañero J C. A ctualización en manejo de la infección urinaria en urgencias. An Pediatr Contin. 2011; 9(1):7-14.

25. Subcommittee on U rinary Tract Infection, Steering Committee on Quality Improvement and $M$ anagement, Roberts K B. U rinary tract infection: clinical practice guideline for the diagnosis and management of the initial UTI in febrile infants and children 2 to 24 months. Pediatrics. 2011; 128(3):595-610.

26. M olina Cabañero JC. A ctualización en manejo de la infección urinaria en urgencias. A n Pediatr Contin. 2011; 9(1):7-14

27. A reses Trapote $R C$, Castillo L aita JA, Escribano Subias J , Fraga Rodriguez GM García Díaz A, García Rodriguez S, et al. Guia de practica clinica sobre infeccion del tracto urinario en la poblacion pediatrica. [monografía en internet]. Zaragoza, España: Plan de Calidad para el Sistema Nacional de Salud del M inisterio de Sanidad, Política Social e I gualdad. Instituto A ragonés de Ciencias de la Salud; 2011 [citado 26 mar 2015]. Disponible en: http://www.guiasalud.es/GPC/ GPC_483_ITU_poblacion_pediatrica_ICS_compl.pdf.
28. Raszka W V, K han O. Pyelonephritis. Pediatr Rev. 2005; 26(10):364-70.

29. Benador N, Siegrist CA, Gendrel D, Greder C, B enador D, A ssicot D, et al. Procalcitonin is a marker of severity of renal lesions in pyelonephritis. Pediatrics. 1998; 102(6): 1422-5

30. Leroy S, Fernandez Lopez A, Nikfar R, Romanello C, B ouissou F, Gervaix A et al. Association of procalcitonin with acute pyelonephritis and renal scars in pediatric UTI. Pediatrics. 2013; 131(5):870-9.

31. M ontini G, Zucchetta P, Tomasi L, Talenti E, Rigamonti W, Picco G, et al. Value of imaging studies after a first febrile urinary tract infection in young children: data from Italian renal infection study 1. Pediatrics. 2009; 123(2):e239-46.

32. B iassoni L, Chippington S. I maging in urinary tract infections: current strategies and new trends. Semin Nucl M ed. 2008; 38(1):56-66.

33. Koyle M A, Shifrin D. Issues in febrile urinary tract infection management. Pediatr Clin North A m. 2012 A ug; 59(4):909-22.

34. M antadakis E, Vouloumanou EK, Georgantzi GG, Tsalkidis A, Chatzimichael A Falagas ME. A cute Tc-99m DM SA scan for identifying dilating vesicoureteral reflux in children: a meta-analysis. Pediatrics. 2011; 128(1):e169-79.

35. Newman TB. The new A merican A cademy of Pediatrics urinary tract infection guideline. Pediatrics. 2011; 128(3):572-5.

36. La Scola C, De Mutiis C, Hewitt IK, Puccio G, Toffolo A, Zucchetta P, et al. Different guidelines for imaging after first UTI in febrile infants: yield, cost, and radiation. Pediatrics. 2013;131(3):e665-71.

37. Hoberman A, Charron M, Hickey RW, Baskin M, Kearney DH, Wald ER. Imaging studies after a first febrile urinary tract infection in young children. N Eng J Med. 2003; 348(3):195-202.

38. Kowalsky RH, Shah NB. Update on urinary tract infections in the emergency department. Curr Opin Pediatr. 2013; 25(3):317-22.

39. Gorelick M, Shaw K. Screening tests for urinary tract infection in children: A meta-analysis. Pediatrics. 1999; 104(5):e54.

40. Duke T, Kelly J, Weber M, English M, Campbell H. Hospital care for children in developing countries: clinical guidelines and the need for evidence. J Trop Pediatr. 2006; 52(1):1-2.

41. Hellerstein S. A cute urinary tract infection--evaluation and treatment. Curr O pin Pediatr. 2006; 18(2):134-8

42. Finnell SM, Carroll AE, Downs SM ; Subcommittee on U rinary Tract Infection. Technical report-Diagnosis and management of an initial UTI in febrile infants and young children. Pediatrics. 2011; 128(3):e749-70.

43. Schaeffer AJ. Recurrent urinary tract infections in infancy: relapses or reinfections?.J U rol. 2002; 168(4 Pt 1):1653-4.

44. Paschke AA, Zaoutis T, Conway PH, Xie D, Keren R. Previous antimicrobial exposure is associated with drug-resistant urinary tract infections in children. $\mathrm{Pe}$ diatrics. 2010; 125(4):664-72.

45. Chevalier I, Benoit G, Gauthier M, Phan V, Bonnin AC, Lebel M H. A ntibiotic prophylaxis for childhood urinary tract infection: a national survey. J Paediatr Child Health. 2008; 44(10):572-8.

46. Keren $\mathrm{R}, \mathrm{C}$ arpenter $\mathrm{M}, \mathrm{G}$ reenfield $\mathrm{S}, \mathrm{H}$ oberman $\mathrm{A}, \mathrm{M}$ athews $\mathrm{R}, \mathrm{M}$ attoo $\mathrm{T}$, et al. Is antibiotic prophylaxis in children with vesicoureteral reflux effective in preventing pyelonephritis and renal scars? A randomized, controlled trial. Pediatrics. Pediatrics. $2008 ; 122(6): 1409-10$

47. Jepson RG, M ihaljevic L, Craig J. Cranberries for treating urinary tract infec tions. Cochrane Database Syst Rev. 2000;(2):CD 001322

48. Stapleton AE, Dziura J, Hooton TM , Cox M E, Yarova-Yarovaya Y, Chen S, et al. Recurrent urinary tract infection and urinary Escherichia coli in women ingesting cranberry juice daily: a randomized controlled trial. M ayo Clin Proc. 2012; 87(2):143-50.

49. Lee SJ, Shim Y H, Cho SJ, Lee JW. Probiotics prophylaxis in children with persistent primary vesicoureteral reflux. Pediatr N ephrol. 2007; 22(9):1315-20.

50. Jodal U, Smellie J M , L ax H, Hoyer PF. Ten-year results of randomized treatment of children with severe vesicoureteral reflux. Final report of the International Reflux Study in Children. Pediatr Nephrol. 2006; 21(6):785-92. 